\title{
Controle de Brachiaria decumbens Stapf com adição de ureia à calda do glifosato ${ }^{1}$
}

\author{
Renato Adriane Alves Ruas², Júlio Cesar Lourenço Lima², Maicon Fábio Appelt² ${ }^{2}$ Luciel Rauni Dezordi²
}

\begin{abstract}
Control of Brachiaria decumbens Stapf

with urea added to the glyphosate spray solution

The addition of nitrogen sources to herbicide spray solutions has been related to improvements in phytosanitary treatments. This study aimed at evaluating the control of Brachiaria decumbens with urea added to the glyphosate spray solution. Treatments consisted of a combination of glyphosate ( $0.0 \mathrm{~g} \mathrm{ha}^{-1}, 360.0 \mathrm{~g} \mathrm{ha}^{-1}, 720.0 \mathrm{~g} \mathrm{ha}^{-1}$ and 1,080.0 $\mathrm{g} \mathrm{ha}^{-1}$ of the a.i.) and urea doses $\left(0.0 \mathrm{~g} \mathrm{~L}^{-1}, 7.5 \mathrm{~g} \mathrm{~L}^{-1}, 15.0 \mathrm{~g} \mathrm{~L}^{-1}\right.$ and $25.0 \mathrm{~g} \mathrm{~L}^{-1}$ of the spray solution), and a control with no application, in a randomized blocks design, in a $4 \times 4$ factorial scheme, with three replications. Applications were carried out with the aid of a $\mathrm{CO}_{2}$ constant pressure sprayer, equipped with a bar for two flat jet nozzles, operating at the pressure of $300.0 \mathrm{kPa}$. Densities and coverage percentages of plants leaves, provided by the jet nozzles drops, were evaluated, as well as the instantaneous gas exchanges, at 12 a.m., at 2, 4, 6 and 11 days after application (DAA), by using a portable infrared gas analyzer. Visual evaluations of control percentage were carried out at 7, 14, 21 and 28 DAA. No difference was observed in the density and coverage of leaves, for the different urea concentrations. The addition of urea to the glyphosate spray solution improved the $B$. decumbens control, regardless the herbicide dose, up to the $25.0 \mathrm{~g} \mathrm{~L}^{-1}$ spray solution concentration. The gas exchange of $B$. decumbens was lower after 6 DAA, in treatments with higher concentrations of urea in the herbicide spray solution, resulting in a higher control level for these treatments.
\end{abstract}

KEY-WORDS: Adjuvants; weed; pesticide application technology.

\section{INTRODUÇÃO}

A interferência de plantas daninhas é um dos fatores que mais afetam a produtividade de culturas anuais e perenes. A baixa produção de plantas submetidas à competição com plantas daninhas ocorre, principalmente, devido ao fato de estas, muitas vezes, serem mais eficientes, quanto ao aproveitamento de

\section{RESUMO}

A adição de fontes nitrogenadas a caldas de herbicidas tem sido relacionada a melhorias em tratamentos fitossanitários. Objetivou-se, neste trabalho, avaliar a eficácia no controle de Brachiaria decumbens, com a adição de ureia à calda do glifosato. Os tratamentos constituíram-se pela combinação de doses de glifosato $\left(0,0 \mathrm{~g} \mathrm{ha}^{-1}, 360,0 \mathrm{~g} \mathrm{ha}^{-1}, 720,0 \mathrm{~g} \mathrm{ha}^{-1} \mathrm{e} 1.080,0 \mathrm{~g} \mathrm{ha}^{-1}\right.$ do i.a.) e de ureia $\left(0,0 \mathrm{~g} \mathrm{~L}^{-1}, 7,5 \mathrm{~g} \mathrm{~L}^{-1}, 15,0 \mathrm{~g} \mathrm{~L}^{-1}\right.$ e $25,0 \mathrm{~g} \mathrm{~L}^{-1}$ de calda) e uma testemunha sem aplicação, em delineamento em blocos casualizados, em esquema fatorial $4 \times 4$, com três repetições. As aplicações foram realizadas com pulverizador de pressão constante de $\mathrm{CO}_{2}$, equipado com barra para duas pontas de jato plano, operando à pressão de $300,0 \mathrm{kPa}$. Foram avaliadas as densidades e percentagem de cobertura das folhas das plantas, proporcionadas pelas gotas produzidas pelas pontas hidráulicas, bem como as trocas gasosas instantâneas às 12 horas, aos 2, 4, 6 e 11 dias após a aplicação (DAA), utilizando-se um analisador infravermelho portátil de gás. Realizaram-se avaliações visuais da percentagem de controle aos 7, 14, 21 e 28 DAA. Não foi observada diferença na densidade e cobertura das folhas, nas diferentes concentrações de ureia. A adição de ureia à calda do glifosato promoveu incrementos no controle de $B$. decumbens, independentemente da dose do herbicida, com o uso de concentrações de até $25,0 \mathrm{~g} \mathrm{~L}^{-1}$ de calda. A troca gasosa de B. decumbens foi menor a partir dos 6 DAA, nos tratamentos com maiores concentrações de ureia na calda do herbicida, resultando em maior controle, nestes tratamentos.

PALAVRAS-CHAVE: Adjuvantes; planta daninha; tecnologia de aplicação de defensivos.

luz, água e nutrientes (Ronchi et al. 2007, Araújo et al. 2010), causando perdas na produtividade e na qualidade do produto final, para os agricultores.

A crescente adoção de sistemas de produção conservacionistas tem por base o revolvimento mínimo do solo e a manutenção da cobertura vegetal em sua superfície. Com este objetivo, o sistema de semeadura direta e o de cultivo mínimo têm sido lar-

1. Trabalho recebido em abr./2012 e aceito para publicação em dez./2012 (n registro: PAT 17873).

2. Universidade Federal de Viçosa (UFV), Campus de Rio Paranaíba, Rio Paranaíba, MG, Brasil.E-mails: renatoruas@ufv.br, julio.lima@ufv.br, maicon.appelt@ufv.br, luciel.dezordi@ufv.br. 
gamente utilizados, por diversos produtores agrícolas (Carvalho et al. 2008).

$\mathrm{Na}$ busca por plantas que proporcionem adequada cobertura do solo, com características favoráveis ao sistema de semeadura direta, as espécies do gênero Brachiaria vêm despertando o interesse de diversos agricultores e pesquisadores (Andrioli 2004, Timossi et al. 2006 e 2007). Entretanto, elas são consideradas importantes plantas daninhas, em algumas culturas perenes (Dias et al. 2004, Souza et al. 2006).

O eficiente manejo da Brachiaria é o ponto chave para o sucesso no estabelecimento de culturas sob semeadura direta. Dentre as diversas formas de manejo existentes, destaca-se o químico, por obter resultados mais rápidos, efetivos e de melhor custo/ benefício. Assim, o controle de plantas daninhas, antes da semeadura direta, permite que a cultura tenha desenvolvimento inicial livre de interferências e impede que ocorram rebrotas e reinfestações na área, facilitando a ação de herbicidas complementares, após a emergência da cultura.

Um dos herbicidas que mais se destacam no controle da Brachiaria é o glifosato. Trata-se de um herbicida muito útil para a adoção em sistemas de baixo impacto ambiental, em razão do seu amplo espectro de controle e baixa toxicidade a organismos não alvos (Rodrigues \& Almeida 2005, Christoffoleti et al. 2008). Trata-se de um herbicida não seletivo, de ação sistêmica, usado no controle de plantas daninhas anuais e perenes e na dessecação de culturas de cobertura (Rodrigues \& Almeida 2005, Timossi et al. 2006). Sua molécula inibe a enzima EPSPs (enol piruvil shiquimato fosfato sintase), que participa da rota de síntese dos aminoácidos aromáticos fenilalanina, tirosina e triptofano. A absorção via cutícula é lenta, pois a cutícula foliar e a membrana plasmática funcionam como barreiras, que limitam a atividade do herbicida (Satchivi et al. 2000). Ademais, possui coeficiente de partição octanol/água extremamente baixo $(-4,1)$, indicando que a molécula tem baixa afinidade por substâncias graxas e altíssima por água (Pedrinho Júnior et al. 2002b), sendo necessário período de quatro a seis horas sem chuvas, após a aplicação, para ocorrer o controle adequado de plantas susceptíveis (Jakelaitis et al. 2001, Pedrinho Júnior et al. 2002a).

Dessa forma, devido à importância do glifosato para a agricultura mundial, estudos têm sido realizados, com o objetivo de avaliar a contribuição de diferentes variáveis em sua eficiência, dentre as quais pode-se destacar a dose, volume de calda, qualidade da água, estádio fenológico das plantas daninhas e atividade de adjuvantes (Gauvrit 2003, Pratt et al. 2003, Ramsdale et al. 2003, Nurse et al. 2008).

Nesse contexto, a adição de fontes nitrogenadas, como adjuvantes à calda do herbicida, tem sido relacionada à redução de doses, ao antagonismo de cátions em água dura e à melhor absorção e translocação da molécula do glifosato (Pratt et al. 2003, Mueller et al. 2006, Carvalho et al. 2008 e 2010). Porém, novos estudos devem ser desenvolvidos, visando a elucidar os meios pelos quais ocorre a interação das fontes nitrogenadas com o glifosato, potencializando a ação do herbicida.

Nesse sentido, a ureia tem sido utilizada em aplicações foliares, como fonte de nitrogênio e, principalmente, como agente facilitador da penetração de nutrientes catiônicos, aniônicos e herbicidas (Carvalho et al. 2010), sendo comumente adicionada ao glifosato, por produtores brasileiros, porém, sem o devido respaldo da pesquisa científica. É provável que, com a redução do antagonismo proporcionado pela presença de sais na calda de pulverização, haja, também, a possibilidade de diminuir a quantidade de glifosato necessária ao controle eficaz de Brachiaria e de outras plantas daninhas, além de aumentar a eficácia de controle (Carvalho 2009).

Este trabalho foi realizado com o objetivo de avaliar a eficácia do controle de Brachiaria decumbens, com a adição de ureia à calda do glifosato.

\section{MATERIAL E MÉTODOS}

O experimento foi realizado no campo experimental da Universidade Federal de Viçosa, Campus de Rio Paranaíba (UFV-CRP), a $1.100 \mathrm{~m}$ de altitude. O solo foi classificado como Latossolo Vermelho, textura argilosa (Embrapa 2006). Aárea experimental estava ocupada com pastagem (Brachiaria decumbens), nos últimos anos, e em estágio pós-florescimento, na ocasião da aplicação dos tratamentos. A matéria seca estimada na área, com base em amostragem, foi de 3,05 $\mathrm{Mg} \mathrm{ha}^{-1}$.

Empregou-se o esquema fatorial $4 \mathrm{x} 4$, no delineamento em blocos casualizados, com três repetições e uma testemunha sem aplicação, totalizando 48 parcelas. Os tratamentos resultaram da combinação entre doses do herbicida glifosato $\left(0,0 \mathrm{~g} \mathrm{ha}^{-1}\right.$, $360,0 \mathrm{~g} \mathrm{ha}^{-1}, 720,0 \mathrm{~g} \mathrm{ha}^{-1}$ e 1.080,0 $\mathrm{g} \mathrm{ha}^{-1}$ do i.a.) e 
concentrações de ureia $\left(0,0 \mathrm{~g} \mathrm{~L}^{-1}, 7,5 \mathrm{~g} \mathrm{~L}^{-1}, 15,0 \mathrm{~g} \mathrm{~L}^{-1}\right.$ e $25,0 \mathrm{~g} \mathrm{~L}^{-1}$ de calda). Cada parcela foi estabelecida com dimensões de $2,0 \mathrm{~m}$ x 5,0 m, com área total de $10,0 \mathrm{~m}^{2}$ e área útil de $8,0 \mathrm{~m}^{2}$, sendo excluídos $0,5 \mathrm{~m}$ de bordadura, nas extremidades de cada parcela.

O preparo da calda, para cada tratamento, foi realizado 30 minutos antes da pulverização. A aplicação dos tratamentos foi efetuada com pulverizador costal pressurizado com $\mathrm{CO}_{2}$, acoplado a uma barra com duas pontas de jato plano (modelo XR 110-02), espaçadas em $0,5 \mathrm{~m}$. O volume de calda utilizado foi de 200,0 $\mathrm{L} \mathrm{ha}^{-1}$, com pressão de trabalho de $300,0 \mathrm{kPa}$ e altura da barra de $0,5 \mathrm{~m}$, a partir do ponto mais alto das plantas de cada parcela.

As condições atmosféricas, durante a execução das aplicações, foram coletadas em uma estação meteorológica, na UFV-CRP, instalada a, aproximadamente, 100,0 $\mathrm{m}$ do local. A velocidade média do vento era de $7,3 \mathrm{~km} \mathrm{~h}^{-1}$, a temperatura de $22^{\circ} \mathrm{C}$ e a umidade relativa do ar de $65 \%$, condições consideradas adequadas, para a aplicação de pesticidas.

Para analisar a percentagem de cobertura e a densidade de gotas produzidas pelas pontas hidráulicas, foram utilizadas etiquetas de papel impregnadas com corante azul de bromofenol, que, na sua forma não ionizada, apresenta coloração amarela e que, em contato com a água, ioniza-se, adquirindo forte coloração azul (Ciba-Geigy 1994). As etiquetas foram dispostas na posição central das parcelas, em quatro tratamentos, compostos pela menor dose de glifosato combinado com as quatro concentrações de ureia.

Após a aplicação, as etiquetas foram escaneadas e processadas com o auxílio do software Image Tool, versão 3.0, obtendo-se o valor da área de cada mancha formada pelas gotas pulverizadas. Em seguida, as áreas das manchas foram processadas com a utilização do software Microsoft Excel, determinando-se a amplitude relativa (SPAN), área de cobertura do alvo (COB) e densidade de gotas (DEN). Determinou-se, também, o percentual de risco de deriva (PRD), por meio do percentual de gotas com diâmetro inferior a $141,0 \mu \mathrm{m}$, como proposto por Mirales \& Hewitt (1997).

Aos 7, 14, 21 e 28 DAA, foram realizadas avaliações visuais da percentagem de controle de $B$. decumbens, em escala onde zero representa a ausência de sintomas e 100 a morte completa de todas as plantas (ALAM 1974).

Em cada parcela experimental, em uma folha totalmente expandida e previamente marcada, foram feitas avaliações instantâneas de trocas gasosas, às 12 horas, aos 2, 4, 6 e 11 dias após a aplicação (DAA) do herbicida, utilizando-se um analisador infravermelho portátil de gás (LICOR 6400XT, Li-COR, Lincoln, EUA), em sistema aberto, com luz artificial saturante

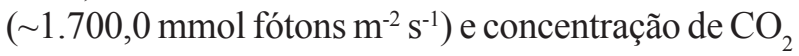
ambiente. Os intervalos das avaliações foram selecionados de modo que houvesse tempo suficiente para que o herbicida atingisse o sítio de ação e iniciasse os primeiros efeitos na planta. As avaliações foram realizadas posicionando-se a folha a ser analisada entre as pinças do aparelho. Em seguida, esperava-se tempo necessário para o registro das trocas gasosas, de acordo com a condição ambiente, no momento da leitura. O aparelho emitia um sinal sonoro, indicando o final do registro da leitura. Os dados eram armazenados para, posteriormente, serem transferidos e processados.

No ato da aplicação, foi quantificada a matéria seca (MS), em cada tratamento, utilizando-se um quadro de $0,25 \mathrm{~m}^{2}(0,5 \mathrm{~m} \times 0,5 \mathrm{~m})$, lançado aleatoriamente em área representativa da parcela, com quatro repetições, onde foi retirada toda a parte aérea das plantas, secas em estufa de circulação forçada de ar, a $70^{\circ} \mathrm{C}$, por 72 horas.

Os dados foram submetidos aos testes de Lilliefors (5\%), para verificar se os valores seguiram a distribuição normal, e de Cochran e Bartlett (5\%), para avaliar a homogeneidade de variâncias, e, quando necessário, foram transformados. Em seguida, foram submetidos à análise de variância, e, quando significativos, à análise de regressão. A escolha dos modelos baseou-se na significância dos coeficientes de regressão e no coeficiente de determinação $\left(\mathrm{R}^{2}\right)$. As análises foram executadas adotando-se a significância estatística de 5\%.

\section{RESULTADOS E DISCUSSÃO}

Verificou-se, pela análise de variância, que as diferentes concentrações de ureia, na calda do herbicida, não apresentaram diferença, para os parâmetros de espectro de gotas avaliados (Tabela 1). Isto indica que o aumento na concentração de ureia, na calda, não promoveu alteração do espectro de gotas da aplicação do herbicida. Para que estas alterações fossem verificadas, seria necessário haver interações físico-químicas na calda do glifosato com a solução de ureia, alterando, sobretudo, a tensão superficial e a pressão de vapor da gota. 
Tabela 1. Amplitude relativa (SPAN), densidade de gotas (DEN), percentual de cobertura do alvo (COB) e percentual de risco de deriva (PRD) proporcionados pela adição de diferentes concentrações de ureia à calda do herbicida (Rio Paranaíba, MG, 2011).

\begin{tabular}{ccccc}
\hline $\begin{array}{c}\text { Concentração de ureia } \\
\text { por litro de glifosato }\end{array}$ & SPAN & DEN & COB & PRD \\
\cline { 3 - 5 } g L $^{-1}$ & & gotas cm $^{-2}$ & \% - \\
\cline { 3 - 5 } 0,0 & 7,79 & 62,47 & 30,20 & 42,59 \\
7,5 & 9,06 & 59,21 & 35,35 & 38,57 \\
15,0 & 9,57 & 52,88 & 34,20 & 41,48 \\
25,0 & 8,05 & 54,61 & 33,96 & 44,61 \\
\hline Média & 8,62 & 57,29 & 33,42 & 41,81 \\
\hline Ajuste de regressão & ns & ns & ns & ns \\
\hline C.V. $(\%)$ & 36,46 & 27,48 & 11,43 & 16,45 \\
\hline
\end{tabular}

${ }^{\text {ns }}$ Não significativo.

Esses dados estão de acordo com Iost (2008), que estudou o efeito da adição de diferentes adjuvantes no tamanho da gota e verificou pouco efeito destes no diâmetro das gotas e na percentagem de cobertura de gotas menores que 100,0 $\mu \mathrm{m}$. Ademais, Cunha et al. (2010) estudaram a adição de adjuvantes na calda e, também, não encontraram efeito significativo destes no diâmetro e no risco potencial de deriva das gotas. Porém, este efeito depende das propriedades físico-químicas da cada adjuvante utilizado, como, por exemplo, a capacidade de romper a tensão superficial da gota e, também, reduzir a pressão de vapor, aumentando a vida média das gotas produzidas (Cunha \& Alves 2009).

Verificou-se que o espectro de gotas produzido foi heterogêneo (SPAN = 8,62) (Tabela 1). É considerado espectro homogêneo aquele que apresenta valores próximos a zero, indicando população de gotas com diâmetros muito próximos. Entretanto, pontas hidráulicas produzem gotas de diversos tamanhos, devido às características físicas do seu processo de formação. Ao passar pelo orifício da ponta, forma-se um filme líquido muito fino e, à medida em que se distancia da ponta, o atrito com o ar torna-se mais intenso, resultando na fragmentação em gotas de diversos tamanhos. Este fato justifica, também, o elevado potencial de deriva observado $(\mathrm{PRD}=41,81 \%)$, pois gotas muito pequenas são passíveis de serem carreadas pelo vento. Entretanto, a ponta produziu densidade $\left(\mathrm{DEN}=57,29\right.$ gotas $\left.\mathrm{cm}^{-2}\right)$ e cobertura $(\mathrm{COB}=33,42 \%)$ sobre as folhas das plantas que podem ser consideradas adequadas, para tratamentos com herbicidas sistêmicos, como o glifosato.

Não foi identificada interação entre as doses de glifosato e as diferentes concentrações de ureia, para todas as avaliações de percentagem de controle. As equações de regressão ajustadas indicam que, independentemente da dose de glifosato, a percentagem de controle de $B$. decumbens elevou-se significativamente, com o aumento da concentração de ureia de até $25 \mathrm{~g} \mathrm{~L}^{-1}$, na calda do herbicida. Observou-se que as concentrações de 7,5 g, 15,0 g e 25,0 g de ureia por litro de glifosato proporcionaram incrementos no percentual de controle de $B$. decumbens, em relação à aplicação do herbicida isoladamente, em todas as épocas de avaliação (Figura 1). Estes resultados corroboram aqueles obtidos em outros trabalhos já realizados, tais como o de Durigan (1992), que constatou que a adição de ureia $\left(0,2 \% ; 500,0 \mathrm{~L} \mathrm{ha}^{-1}\right.$ de calda) proporcionou redução na dose de glifosato em 360,0 g i.a. ha ${ }^{-1}$, para controle de Panicum maximum. Pedrinho Júnior et al. (2002b) observaram que a adição de ureia $\left(50,0 \mathrm{~g} \mathrm{~L}^{-1}\right.$ de calda) ao glifosato aumentou a velocidade de ação do herbicida. Carvalho et al. (2008) concluíram que a adição de ureia ( $6,0 \mathrm{~g} \mathrm{~L}^{-1}$ de calda) melhorou o controle de trapoeraba pelo glifosato, na dose de 360,0 g i.a. ha-1 .

De acordo com Durigan (1992), a ureia atravessa, com relativa facilidade, a cutícula das folhas. Mesmo sem receber energia metabólica, passa do apoplasto para o simplasto foliar, por difusão facilitada, resultante do acúmulo de energia cinética pelas moléculas. A ureia também pode romper algumas ligações éster, éter e di-éter da cutina, o que contribui para a maior absorção de outros elementos presentes na calda, como o glifosato, devido ao aumento dos espaços de entrada.

As trocas gasosas instantâneas não sofreram redução significativa, até $4 \mathrm{DAA}$, demonstrando baixa redução na taxa fotossintética causada pelo herbicida, nos primeiros dias após a aplicação. Os valores observados foram de $8,18 \mu \mathrm{mol} \mathrm{CO}_{2} \mathrm{~m}^{-2} \mathrm{~s}^{-1} \mathrm{e}$ 


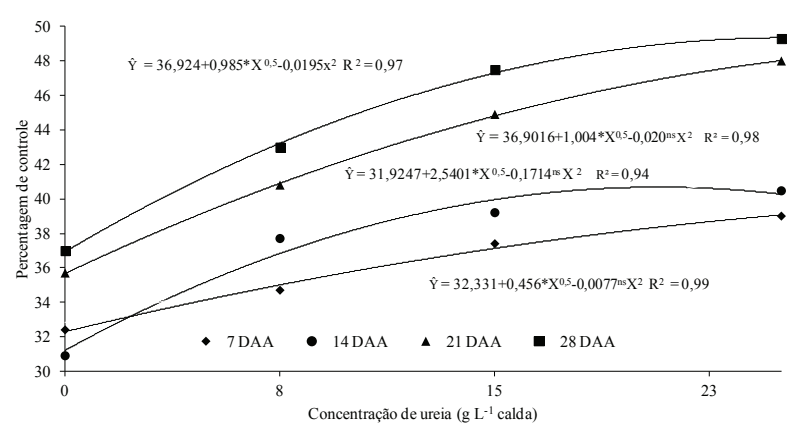

Figura 1. Percentagem de controle de B. decumbens, em função da concentração de ureia na calda do herbicida, avaliada aos 7, 14, 21 e 28 dias após a aplicação (DAA) (Rio Paranaíba, MG, 21/09/2011).

$4,44 \mu \mathrm{mol} \mathrm{CO}_{2} \mathrm{~m}^{-2} \mathrm{~s}^{-1}$, aos 2 e 4 DAA do glifosato, respectivamente. Isto se deve ao tempo gasto pelo glifosato para atingir o seu sítio de ação, inibir a rota metabólica e comprometer o metabolismo da planta, o qual leva alguns dias para acontecer. Cunha (2005) relata que algumas plantas levam até 20 dias após a aplicação do glifosato para morrer, sendo a estabilidade in vivo deste herbicida uma importante característica, que contribui para seus efeitos fitotóxicos irreversíveis.

Houve interação significativa entre as diferentes concentrações de ureia e doses de glifosato, a 5\%, pelo teste F. Logo, procedeu-se ao estudo da análise de regressão múltipla, sendo que os coeficientes selecionados apresentaram resposta quadrática para a maioria dos tratamentos. Independentemente da dose de glifosato empregada, as concentrações de ureia proporcionaram redução na atividade fotossintética, em todas as épocas de avaliação. Aos 6 DAA, a dose de 720,0 g i.a. ha- ${ }^{-1}$ do glifosato, associada a doses de $15,0 \mathrm{~g} \mathrm{~L}^{-1}$ e $25,0 \mathrm{~g} \mathrm{~L}^{-1}$ de ureia, proporcionou maior redução nas trocas gasosas, em relação à aplicação da dose sem a adição de ureia (Figura 2). Verificou-se que esta redução também foi superior, quando se aplicou a dose isolada de 1.080,0 g i.a. ha-1 de glifosato. Nesta dose do herbicida, a aplicação de $25,0 \mathrm{~g} \mathrm{~L}^{-1}$ proporcionou a maior redução da atividade fotossintética da Brachiaria.

Aos 11 DAA, as observações verificadas aos 6 DAA se confirmaram. Independentemente da dose de ureia adicionada às doses de 720,0 g i.a. ha ${ }^{-1} \mathrm{e}$ $1.080,0$ g i.a. ha ${ }^{-1}$ de glifosato, houve redução da assimilação líquida de $\mathrm{CO}_{2}$ (Figura 3).

A redução na troca gasosa, observada tanto aos 6 DAA quanto aos 11 DAA, provavelmente tenha ocorrido devido à diminuição de compostos essenciais ao metabolismo fotossintético da planta,

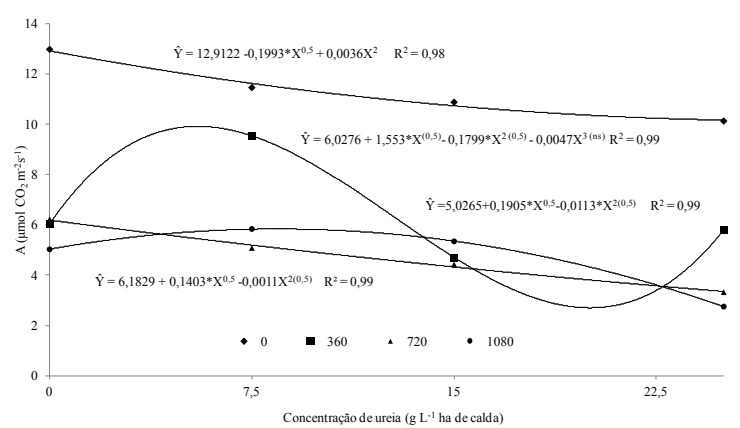

Figura 2. Trocas gasosas instantâneas de $\mathrm{CO}_{2}(A)$ pela $B$. decumbens, aos 6 DAA de glifosato, nas concentrações de $0,0 \mathrm{~g} \mathrm{ha}^{-1}$, $360,0 \mathrm{~g} \mathrm{ha}^{-1}, 720,0 \mathrm{~g} \mathrm{ha}^{-1}$ e 1.080,0 $\mathrm{g} \mathrm{ha}^{-1}$ do i.a. (Rio Paranaíba, MG, 21/09/2011).

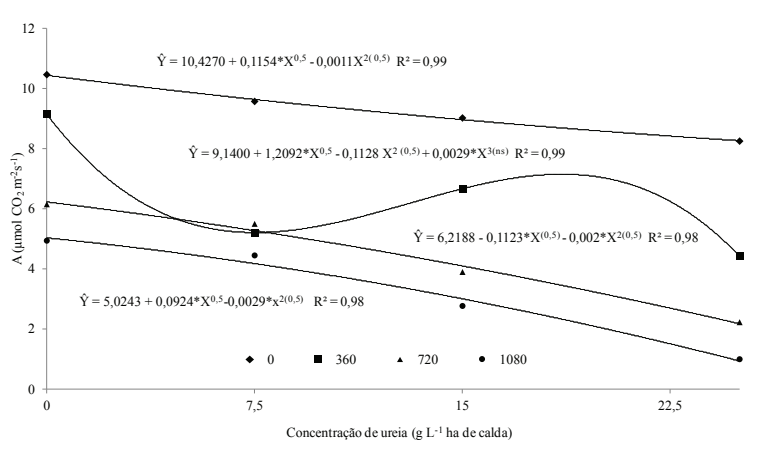

Figura 3. Trocas gasosas instantâneas de $\mathrm{CO}_{2}(A)$ pela $B$. decumbens, aos 11 DAA de glifosato, nas concentrações de $0,0 \mathrm{~g} \mathrm{ha}^{-1}$, $360,0 \mathrm{~g} \mathrm{ha}^{-1}, 720,0 \mathrm{~g} \mathrm{ha}^{-1}$ e $1.080,0 \mathrm{~g} \mathrm{ha}^{-1}$ do i.a. (Rio Paranaíba, MG, 26/09/2011).

como a vitamina $\mathrm{E}$, ácido indol acético (AIA), antocianinas, flavonas e isoflavonas e, especialmente, plastoquinonas, as quais participam diretamente da cadeia fotossintética transportadora de elétrons. Todos estes compostos são sintetizados a partir dos aminoácidos fenilalanina, tirosina ou triptofano, os quais têm sua síntese inibida pelo glifosato, podendo ser acelerada pela presença de compostos nitrogenados da calda (Velini et al. 2009).

\section{CONCLUSÕES}

1. O espectro de gotas de pulverização produzido pela ponta XR 110-02 não foi afetado pela presença de ureia na calda de pulverização do glifosato.

2. A adição de ureia à calda do herbicida glifosato promoveu incrementos no controle de $B$. decumbens, no campo, com o uso de concentrações de até 25,0 $\mathrm{g} \mathrm{L}^{-1}$ de calda. 
3. O controle de $B$. decumbens, aplicando-se glifosato na dose de 720,0 g i.a. ha ${ }^{-1}$, associada a $25,0 \mathrm{~g} \mathrm{~L}^{-1}$ de calda, foi superior ao controle proporcionado pela aplicação isolada de $1.080,0$ g i.a. ha ${ }^{-1}$ do herbicida.

4. A troca gasosa instantânea proporcionada pela aplicação de ureia, nas concentrações de $15,0 \mathrm{~g} \mathrm{~L}^{-1}$ e 25,0 $\mathrm{g} \mathrm{L}^{-1}$ da calda de glifosato, em plantas de $B$. decumbens, foi menor a partir dos 6 DAA.

\section{REFERÊNCIAS}

ANDRIOLI, I. Plantas de cobertura em pré-safra à cultura do milho em plantio direto, na região de Jaboticabal - SP. 2004. 78 f. Tese (Livre Docência)-Faculdade de Ciências Agrárias e Veterinárias, Universidade Estadual Paulista, Jaboticabal, 2004.

ARAÚJO, F. C. et al. Largura da faixa de controle de plantas daninhas em lavouras de Coffea arabica L. recémtransplantadas do Alto Paranaíba - MG. In: CONGRESSO BRASILEIRO DA CIÊNCIA DAS PLANTAS DANINHAS, 27., 2010, Ribeirão Preto. Anais... Londrina: SBCPD, 2010. p. 2688-2692.

ASOCIACIÓN LATINOAMERICANO DE MALEZAS (ALAM). Recomendaciones sobre unificación de los sistemas de evaluacion en ensayos de control de malezas. Asociación Latinoamericana de Malezas, Bradenton, v. 1, n. 1, p. 35-38, 1974.

CARVALHO, S. J. P. Dessecação de plantas daninhas com o herbicida glyphosate associado a fertilizante nitrogenado. 2009. 116 f. Tese (Doutorado em Ciências) - Escola Superior de Agricultura Luiz de Queiroz, Universidade de São Paulo, Piracicaba, 2009.

CARVALHO, S. J. P. et al. Adição simultânea de sulfato de amônio e ureia à calda de pulverização do herbicida glyphosate. Planta Daninha, Viçosa, v. 28, n. 3, p. 575584, 2010.

CARVALHO, S. J. P. et al. Glifosato aplicado com diferentes concentrações de ureia ou sulfato de amônio para dessecação de plantas daninhas. Pesquisa Agropecuária Brasileira, Brasília, DF, v. 43, n. 11, p. 1501-1508, 2008.

CHRISTOFFOLETI, P. J. et al. Glyphosate sustainability in South American cropping systems. Pesticide Management Science, West Sussex, v. 64, n. 1, p. 422-427, 2008.

CIBA-GEIGY: water-sensitive paper for monitoring spray distribution. Basle: Ciba-Geigy Ltd., 1994.

CUNHA, C. S. M. Comparação de métodos na detecção de sementes de soja geneticamente modificada resistente ao glifosato. Revista Brasileira de Sementes, Pelotas, v. 27, n. 1, p. 167-175, 2005.
CUNHA, J. P. A. R.; ALVES, G. S. Características físicoquímicas de soluções aquosas com adjuvantes de uso agrícola. Interciência, Caracas, v. 34, n. 9, p. 655659, 2009.

CUNHA, J. P. A. R.; BUENO, M. R.; FERREIRA, M. C. Espectro de gotas de pontas de pulverização com adjuvantes de uso agrícola. Planta Daninha, Viçosa, v. 28, n. esp., p. 1153-1158, 2010.

DIAS, G. F. S.; ALVES, P. L. C. A.; DIAS, T. C. S. Brachiaria decumbens suppresses the initial growth of Coffea arabica. Scientia Agricola, Piracicaba, v. 61, n. 6, p. 579-583, 2004.

DURIGAN, J. C. Efeito de adjuvantes na calda e no estádio de desenvolvimento das plantas daninhas no controle do capim-colonião (Panicum maximum) com glifosato. Planta Daninha, Viçosa, v. 10, n. 1/2, p. 39-44, 1992.

EMPRESA BRASILEIRA DE PESQUISA AGROPECUÁRIA (Embrapa). Centro Nacional de Pesquisa de Solos. Sistema brasileiro de classificação de solos. 2. ed. Rio de Janeiro: Embrapa Solos, 2006.

GAUVRIT, C. Glyphosate response to calcium, ethoxylated amine surfactant, and ammonium sulfate. Weed Technology, Lawrence, v. 17, n. 4, p. 799-804, 2003.

IOST, C. A. R. Efeito de adjuvantes nas propriedades fisicoquímicas da água e na redução de deriva em pulverizações sobre diferentes espécies de plantas daninhas. $2008.63 \mathrm{f}$. Dissertação (Mestrado em Agronomia) - Universidade Estadual Paulista, Botucatu, 2008.

JAKELAITIS, A. et al. Controle de Digitaria horizontalis pelos herbicidas glifosato, sulfosate e glifosato potássico submetidos a diferentes intervalos de chuva após a aplicação. Planta Daninha, Viçosa, v. 19, n. 2, p. 279285, 2001.

MIRALES, A.; HEWITT, A. J. The international (BCPC) spray pulverization system including a drift potential factor. In: BRIGHTON CROP PROTECTION CONFERENCE WEEDS, 1., 1997, Brighton. Proceedings... Surrey: British Crop Protection Council, 1997. p. 371-80

MUELLER, T. C. et al. Comparison of glifosato salts (isopropylamine, diammonium and potassium) and calcium and magnesium concentrations on the control of various weeds. Weed Technology, Lawrence, v. 20, n. 3, p. 164-171, 2006.

NURSE, R. E. et al. Annual weed control may be improved when AMS is added to below-label glyphosate doses in glifosato-tolerant maize (Zea mays L.). Crop Protection, Tulare, v. 27, n. 2, p. 452-458, 2008.

PEDRINHO JÚNIOR, A. F. F. et al. Momento da chuva após a aplicação e a eficácia dos herbicidas sulfosate e glifosato aplicados em diferentes formulações. Planta Daninha, Viçosa, v. 20, n. 1, p. 115-123, 2002a. 
PEDRINHO JÚNIOR, A. F. F. et al. Influência da chuva na eficácia do glifosato em mistura com adjuvantes na dessecação de plantas daninhas. Planta Daninha, Viçosa, v. 20 , n. 2 , p. $263-271,2002$ b.

PRATT, D.; KELLS, J. J.; PENNER, D. Substitutes for ammonium sulfate as additives with glyphosate and glufosinate. Weed Technology, Lawrence, v. 17, n. 3, p. 576-581, 2003.

RAMSDALE, B. K.; MESSERSMITH, C. G.; NALEWAJA, J. D. Spray volume, formulation, ammonium sulfate, and nozzle effects on glyphosate efficacy. Weed Technology, Lawrence, v. 17, n. 3, p. 589-598, 2003.

RODRIGUES, B. N.; ALMEIDA, F. S. Guia de herbicidas. 5. ed. Londrina: Ed. dos Autores, 2005.

RONCHI, C. P.; TERRA, A. A.; SILVA, A. A. Growth and nutrient concentration in coffee root system under weed species competition. Planta Daninha, Viçosa, v. 25, n. 4, p. 679-687, 2007.
SATCHIVI, N. M. et al. Absorption and translocation of glifosato isopropylamine and trimethysulfonium salts in Abutilon theophrasti and Setaria faberi. Weed Science, Champaign, v. 48, n. 6, p. 675-679, 2000.

SOUZA, L. S. et al. Efeitos das faixas de controle de Brachiaria decumbens no desenvolvimento inicial e na produtividade do cafeeiro (Coffea arabica). Planta Daninha, Viçosa, v. 24, n. 2, p. 715-720, 2006.

TIMOSSI, P. C.; DURIGAN, J. C.; LEITE, G. J. Eficácia de glifosato em plantas de cobertura. Planta Daninha, Viçosa, v. 24, n. 2, p. 475-480, 2006.

TIMOSSI, P. C.; DURIGAN, J. C.; LEITE, G. J. Formação de palhada por brachiarias para adoção do sistema plantio direto. Bragantia, Campinas, v. 66, n. 4, p. 617-622, 2007.

VELINI, E. D. et al. Modo de ação do glifosato. In: VELINI, E. D. et al. (Eds.). Glifosato. Botucatu: FEPAF, 2009. p. 113-134. 